\title{
NETWORK CENTRISM OPTIMIZATION OF EXPEDITIOUS SERVICE OF ELEMENTS OF THE POWER SUPPLY SYSTEM
}

\begin{abstract}
Purpose. Development of precision selection criteria of options of technical realization of effective active and adaptive system of expeditious service of elements of a power supply system in the conditions of network-centric management. Methodology. In development of power supply systems their evolution from the elementary forms using elementary network technologies and models of interactions in power to more irregular shapes within the concept of Smart Grid with elements of network-centric character is observed. This direction is based on Internet-technologies of the last generation, and realize models of power activity which couldn't be realized before. Results. The number of possible options of active and adaptive system of expeditious service of elements of a power supply system is usually rather big and it is difficult to choose the acceptable option by direct search. Elimination of admissible options of the technical realization constructed on the principles of a network centrism means application of the theory of multicriteria optimization from a position of discrete programming. The basis of procedure of elimination is made by algorithm of an assessment of system by criterion of accuracy. Originality. The case of an assessment of the precision characteristic of system at restrictions for the set accuracy is connected with need of decomposition of requirements of all system in general and on separate subsystems. For such decomposition the ratios connecting the accuracy of functioning of a separate subsystem with variations of parameters of all system, and also with precision characteristics of subsystems of the lower levels influencing this subsystem are received. Practical value. In the conditions of the network-centric organization of management of expeditious service of elements of a power supply system elimination of options of subsystems when using precision criterion allows to receive the maximum number of essentially possible options of system of service taking into account the accepted service strategy. References 8.
\end{abstract}

Key words: network-centric managements, precision criterion, expeditious service, element of technical realization, output variable of a subsystem.

В статье уделено внимание вопросам использования сетецентрического подхода при формировании активноадаптивной системы оперативного обслуживания элементов энергосистемы в условиях идеологии Smart Grid. Определен точностной критерий отсева вариантов технической реализации этой системы, реализующей концепцию «обслуживания на основе отклика». Библ. 8.

Ключевые слова: сетецентрическое управления, точностной критерий, оперативное обслуживание, элемент технической реализации, выходная переменная подсистемы.

Introduction and problem definition. Today in Ukraine there is a growing interest in the rapidly developing in the last decade throughout the world toward science and technology innovation transform electric power based on the new Smart Grid concept. State structures in most countries consider Smart Grid as an ideology of national power development programs, energy companies - as a base for sustainable innovative modernization of its activity [1-3].

At the same time, a number of problems of improving the power grid management, taking into account the recent experience of energy reforming are developed not enough [4]. The development of an integrated concept of the formation of adaptive control structure and power system information and intellectual bases of increase of efficiency of management techniques in the framework of a customer-oriented approach in the Smart Grid concept is an important and urgent issue of reforms in the energy sector of Ukraine.

Analysis of last investigations and publications. Smart Grid technology helps to create a next-generation power grid, which will allow power companies to effectively manage the production and consumption of electricity. Smart Grid is a system delivering electricity from generating energy enterprises to consumers, with an integrated communication and information technologies and providing improved transparency of the energy system, high-quality customer service and providing environmental benefits [5].

Despite the concept of smart grid can be interpreted in different ways, it is obvious that an intelligent communications network is the basis of smart grid. Enterprises of power industry are investing in communications networks to improve the situational awareness of the resources for the purpose of power system automation, integration of systems and control [6].

Intellectual energy value lies in the fact that electric power companies will be able to «smooth out» the need for electricity in times of peak load, eliminate the use of hot spares and reduce the need for long-term investment in additional generation companies, as well as reduce the need for other investments, such as system reorganization to improve performance [7].

Platform for advanced energy systems constitute intellectual elements that are at the level of the digital technologies that electric power companies were added to the traditional analog and modern infrastructure of the energy system. 
In modern power systems most acute problems are of reliability, safety and efficiency of power plants on the basis of the organization of operational management. The aim of this process is the uninterrupted supply of electricity to consumers of adequate quality, including the task of daily schedules of power plants, maintenance of current conditions, the output of the equipment to be repaired and the elimination of the emergency power system conditions [8]. Development of optimization methods will solve the important problem of optimal organization of the system of operational maintenance and management of its energy system as a component of the structure of operational management within the customer-oriented approach Smart Grid concept.

The goal of investigations is the development of precision criteria for the selection of technical options for the effective implementation of the active-adaptive grid system of operational service elements in a networkcentric control.

Main materials of investigations. In the development of power systems observed their evolution from the simplest forms, using basic networking technologies and replicate traditional models of information interactions in the energy sector, to more complex forms within the Smart Grid concept with elements of network-centric nature. This direction is based on the latest generation of Internet technologies, and implements models of energy-related activities, which previously could not be realized. Existing scientific developments in this area have not yet formed an integrated security model of functioning of a multilevel set of software and hardware complexes of operational dispatch and automatic power systems with the flexibility to manage intellectual elements (activeadaptive) network with increasing automation of volume and an increase in the quantitative and qualitative collection of characteristics, handling, storage, distribution information.

With regard to energy network centrism is used as a term associated with the operational management of the power grid in a single information and communication management space, we consider the union of dissimilar objects act as a system, and a discrete manner how some segments of unified management of distributed network. In this case, network centrism is the organizing principle of the operational control system power supply system, which allows to realize the mode of situational awareness due to the formation and maintenance of the same for all tiers of an integrated management, contextual information environment and inclusion in the process of continuous updating of the greatest possible number of primary sources of information.

Network-centric approach to the construction of information system in the power industry should be based on the creation of equal geographically distributed nodes that perform different functions, and allows users to work with applications and databases through a browser from any location and from any device connected to global telecommunication networks. Network-centric system should allow to bind to a single system interface and database management, monitoring and development control decisions for the use of various software applications regardless of location of objects and subjects of management.

Ukrainian information system requires a higher level of structural and parametric elements of the organization and the energy system should be developed based on the principles of functioning of large systems. However, this requires the restructuring not only the merging of local power system elements, but also the entire global information network (a set of distributed energy facilities).

The solution of the problem is complicated by the presence of weak and at the same time, extensive information management connections over large areas, which limits the ability to collect and analyze large data flows. That is, in our country, its regions and cities require technical and organizational support for a new level of structural and parametric elements of the organization of energy systems, including taking into account the promising development.

Taking the above into consideration, within the framework of improving the structural and parametric organization of energy systems based on active-adaptive electric networks as the primary network infrastructure, new electric power it is necessary to provide:

- creation of a single adaptive management information network within the intellectual electric power system of Ukraine, in order to achieve the sustainable development of electric power strategic indicators;

- the development, integration and access to industry databases based on the information gathered and the introduction of smart electricity grids;

- development and implementation of information monitoring which allows you to plan and allocate resources to the tasks, and provide control over the achievement of results, taking into account the territorial management priorities;

- determination of conditions, the general principles of the energy market regulation techniques based on «Smart Grid - Opportunities», providing high efficiency of state regulation and market self-regulation - based on intelligent electrical power system of Ukraine with the active-adaptive grid power systems that solve the problem the introduction of the new market organizationeconomic nature, including new formats of energy consumer actions;

- implementation of feedback mechanisms between the government regulation and energy companies on the basis of a fundamentally new class of intelligent distributed management environments based on Smart Grid and related organizational change of management techniques.

The specific implementation of the principle of network centrism in structural-parametric elements of the 
organization of power systems provides the fulfillment of certain conditions. The first condition is, above all, the presence of the stable type of communication from the head of any rank in any place, wherever he may be at the moment. The second condition - it should be possible to access information on the current response of the energy system changes its state under the influence of various factors. The next condition is the possibility of replay for analysis guidelines and to take the necessary decisions for displaying the information received in a variety of applications. In a word, the state of the power system information should be presented in a form suitable for analysis, recognition, transmission, distribution and storage.

Network-centric management system with the development of the technical component of the overall process is constantly being improved and developed. It should be noted that the network-centric management system in its entirety, but there is only elements of the system, but they are constantly being improved.

Specificity of the organization of operational management of energy systems implies an adaptive operational service. Among the activities of operational services should be allocated grid complex of works on maintenance of the required mode of operation of the power elements, the production of switches, inspection equipment, preparation for production of repair, maintenance of equipment.

The implementation of network-centric energy system of governance will build adaptive operational services based on the concept of «service system on the basis of response» (SSR). Implementation of the SSR concept aims to service a particular object (digital substation, power lines, power system status monitoring subsystem elements, etc.) located in a particular area and at a particular time, and which currently require operational services in accordance with the response of the energy system.

Technical implementation of effective activeadaptive grid system of operational maintenance (SOM) built on the principles of network centrism based on the supremacy of communication systems that enable realtime to receive and transmit information packets huge variety of customers, including centralized and distributed transmission. The peculiarity of this system lies in the fact that the information in the system hangs, and it allows you to access it without additional time.

A management system implemented in the SOM should be based on developed and implemented in the practice of software products on the intellectual level, the so-called common design models (tasks) combined in a single system.

These components are the basis for formulation of the problem for the development of network-centric, and SOM is the cornerstone of the network centrism. In a single population in the synthesis of SOM are executive digital elements, means of communication, ways and forms of SOM.
The embodiment of a network-centric concept of the SSR in the proposed ESR is inextricably linked with the use of unmanned aerial vehicle (UAV) - quadrocopters. This is dictated by the rapid development of various power equipment diagnostic methods, such as the power and the switching and control equipment and protection in connection with the high cost of direct and indirect losses as a result of accidents.

The development of modern methods of diagnosis allows a high degree of probability to determine the actual condition of the equipment and to predict its change in the near future. However, modern diagnostic equipment is very expensive, which hinders its complete set of each object. It should be noted that the proper organization of work can significantly reduce of diagnostic costs.

An example of such an organization could be the implementation of a special SOM, being composed of UAVs to carry out thermal imaging inspection of substation equipment, optical inspection supporting-rod and hanging insulation, examination of technical condition of transformers and auto-transformers, and a number of other works.

Presence of UAV determines ways of formation of administrative decisions regarding the structure of the power system to adapt to the results of SOM activities of the SSR concept. Screening valid options involves the use of the theory of multi-criteria optimization with discrete programming position. The number of options is usually quite large and select the appropriate solution by brute force is rather difficult. We define the basic provisions of the procedure for constructing options dropout SOM which implements the management decisions adopted within the framework of the SSR.

The basis of this procedure is evaluating options of SOM algorithm according to the criterion of accuracy. In our case it is the concept of precision is very important in management decisions as well as the use of drones as a source of information about the state of the power system elements introduces some degree of uncertainty.

Accuracy of SOM operation as a whole will be judged by the values of deviations of output variables from the set of software subsystems values of the $n$-th level calculated in accordance with the equations of state at the time $t_{n}+1=T$ :

$$
\begin{gathered}
\Delta y_{n h}^{h \alpha}\left(v_{i}\right)=\left|y_{n h}^{h \alpha}\left(v_{i}\right)_{T}-y_{n h(0)}^{h \alpha}(T)\right| \\
\left(h \in I_{n}, \alpha=1, \ldots, \alpha_{n h}^{h}\right)
\end{gathered}
$$

where $y_{n h}^{h \alpha}\left(v_{i}\right)_{T}$ is the value of the $\alpha$-th component of the output variable of the $h$-th subsystem of the $n$-th level of SOM at time $T$ for variant $v_{i} \in V ; y_{n h(0)}^{h \alpha}(T)$ is the given program value of the output variable of the subsystem of the $n$-th level of SOM; $\Delta y_{n h}^{h \alpha}\left(v_{i}\right)$ is the value of deviation of the output variable of the subsystem of the $n$-th level of SOM. 
Here, the set of technical implementation options of the designed SOM is determined as:

$$
V=\left\{v_{i}\right\}=\prod_{i=1}^{M} V_{i} .
$$

The values of the output variables subsystems of the $n$-th level of SOM depend on the types of control laws defined by the SSR strategy; of the accuracy characteristics of elements of the technical implementation of an appropriate control law, defines a set of $I_{n}$ (for $\left.h \in I_{n}\right)$ ) subsystems of the $n$-th level of SOM; output variables $y_{n-k}=\left(t_{n}\right)$ of subsystems of $n$ - $k$-th levels $\forall k \in K_{n h}$. Variables $y_{n-k}=\left(t_{n}\right)$ also depend on the accuracy characteristics of the elements of the technical implementation of the control law of the subsystem of the $n$ - $k$-th level of output variables of the previous level of SOM. Overall, therefore, the accuracy of the whole system depends on the operation of all subsystems levels, i.e. on a variety of the set $V$.

Two cases of estimation of the system accuracy characteristic are possible: the first one - when it is necessary to find a variant of the system $v_{i} \in V$ minimizing the value $\Delta y_{n h}^{h \alpha}\left(v_{i}\right)$, the second one - when this value should not exceed the given one:

$$
\Delta y_{n h}^{h \alpha}\left(v_{i}\right) \leq \varepsilon_{n h}^{h \alpha}, \quad\left(h \in I_{n}, \alpha=1, \ldots, \alpha_{n h}^{h}\right),
$$

where $\varepsilon_{n h}^{h \alpha}$ is a non-negative value that characterizes the degree of closeness of $\alpha$-th output coordinates of the $h$-th subsystem of the $n$-th level of SOM and its program value.

In more detail, consider the second case, as typically specified in the design constraints on some variables output subsystem components that operate at the last time interval.

We assume that each $q$-th type of element of the SOM technical realization is characterized by nominal value of the parameter $p_{q}^{0}$ and a set $\Delta p_{q\left(\zeta_{q}\right)}$ $\left(\zeta_{q} \in 1, \ldots, \zeta_{q}^{0}\right)$ of possible variants of this parameter determined by different modifications of the set $E_{q}\left(\Delta p_{q}\right)=\left\{\Delta p_{q\left(\zeta_{q}\right)} \forall \zeta_{q} \in 1, \ldots, \zeta_{q}^{0}\right\}$. Then, a table of given errors will correspond to the separate variant of the SOM realization:

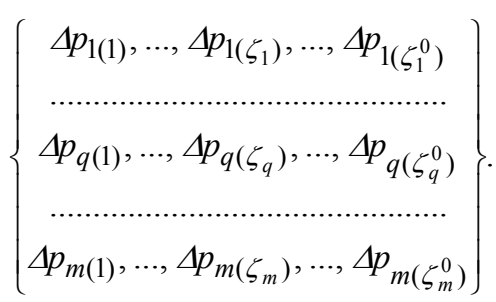

We determine the vector of parameters of dimension $q_{i l\left(\zeta_{l}\right)}$ as

$$
p_{i l\left(\zeta_{l}\right)}=\left\{p_{q}^{0} \pm \Delta p_{q} \forall q \in I_{i l\left(\zeta_{l}\right)}\right\},
$$

corresponding to elements of the SOM technical realization of the set $I_{i l\left(\zeta_{l}\right)}$ for the control low $u_{i l\left(\zeta_{l}\right)}$.
We write solution of the system of differential equations for the $l$-th subsystem of the $i$-th level in the form:

$$
\begin{aligned}
y_{i l}^{j}\left(t, v_{j}^{i l}\right)= & F_{i l\left(\zeta_{l}\right)}^{j}\left(u_{i l\left(\zeta_{l}\right)}(t), p_{i l\left(\zeta_{l}\right)}, y_{i l(0)}^{j}\right) \\
& \left(k \in K_{i l}, q \in I_{i-k}^{l}\right),
\end{aligned}
$$

where $v_{j}^{i l}$ is the part of variant $v_{j} \in V$ on which the value of the output variable of the $l$-th subsystem of the $i$-th level depends; $y_{i l(0)}^{j \alpha}=y_{i-k, q}^{l \lambda}\left(t_{i}\right)\left(k \in K_{i l}\right)$ are the initial conditions for the initial differential equations which are values of output variables of the subsystem of the $i-k$-th levels $\forall k \in K_{i l}$ connected by the $l$-th subsystem of the $i$-th level $\left(\alpha=1, \ldots, \alpha_{i l}^{j}\right) ; F_{i l\left(\zeta_{l}\right)}^{j}$ is vector function whose components are continuous functions of their arguments belonging to the class of discrete optimization problems.

Vector function $F_{i l\left(\zeta_{l}\right)}^{j}$ components have non-zero first derivatives in a neighborhood of the point $\left(y_{i-k, q}^{l}\left(t_{i}\right), p_{i l\left(\zeta_{l}\right)(0)}\right)$ defined by the nominal values of parameters and initial conditions. It should be of a variety of possible options of the SOM $v_{i} \in V$ creation which are characterized as forms of control laws in each of the subsystems, as well as errors in the technical implementation of the elements, select those that meet criteria (1).

Direct construction of all variants of the set $V$ with the assessment of their accuracy criterion (1) makes it necessary to integrate the system of initial differential equations and obtain solutions of the type (2) for all subsystems. This is due to a large amount of calculation, which does not allow to select the appropriate version of the system in the given timeframe. In this connection there is need to develop prior dropout rules both types of control laws in accordance with the SSR strategy and elements of the technical implementation of the SOM. This is due to the need for the decomposition of requirements on the system as a whole, determined by the relation (1), to the requirements for individual subsystem type:

$$
\Delta y_{i l}^{j \alpha}=\left|y_{i l}^{j \alpha}\left(v_{j}^{i l}\right)\right|_{t_{i+1}}-y_{i l(0)}^{j \alpha}(t+1) \mid \leq \varepsilon_{i l}^{j \alpha},
$$

where $\varepsilon_{i l}^{j \alpha}$ is the closeness of the $\alpha$-th component of the output variable of the $l$-th subsystem of the $i$-th level; $\left.y_{i l}^{j \alpha}\left(v_{j}^{i l}\right)\right|_{t_{i+1}}$ is determined from the equations describing behavior of the $l$-th subsystem of the $i$-th level.

For such a decomposition is necessary to obtain relations between the accuracy of the functioning of a separate subsystem with variations SSR parameters as well as lower levels of accuracy characteristics of subsystems that affect this subsystem.

In order to output variables of each $l$-th subsystem of the $i$-th level described by a vector function whose components are continuously differentiable convex or 
concave function defined on a set of parameters $p_{i l\left(\zeta_{l}\right)}$ and initial conditions $y_{i l(0)}^{j}$ that satisfy the constraints of the form (3), enough to vector deviation parameters and initial conditions of the nominal values

$$
\begin{gathered}
p_{i l\left(\zeta_{l}\right)(0)}=\left\{p_{i l\left(\zeta_{l}\right)(0)}^{q}\right\} \quad\left(q=1, \ldots, q_{i l\left(\zeta_{l}\right)}\right), \\
y_{i l(0)}^{j}=\left\{y_{i l(0)}^{j \alpha}\right\} \quad\left(\alpha=1, \ldots, \alpha_{i l}^{j}\right),
\end{gathered}
$$

meet inequalities

$$
\begin{gathered}
\Delta p_{i l\left(\zeta_{l}\right)}^{q}=\left|p_{i l\left(\zeta_{l}\right)}^{q}-p_{i l\left(\zeta_{l}\right)(0)}^{q}\right| \leq \varepsilon_{i l\left(\zeta_{l}\right)}^{q} ;\left(q=1, \ldots, q_{i l\left(\zeta_{l}\right)}\right), \\
\Delta y_{i l}^{j \alpha}=\left|y_{i l}^{j \alpha}-y_{i l(0)}^{j \alpha}\right| \leq \varepsilon_{i l}^{j \alpha} ;\left(\alpha=1, \ldots, \alpha_{i l}^{j}\right),
\end{gathered}
$$

where $\varepsilon_{i l\left(\zeta_{l}\right)}^{q} ;\left(q=1, \ldots, q_{i l\left(\zeta_{l}\right)}\right)$ и $\varepsilon_{i l}^{j \alpha} ;\left(\alpha=1, \ldots, \alpha_{i l}^{j}\right)-$ belong the region:

$$
D_{i l\left(\zeta_{l}\right)}=\bigcap_{\alpha=1}^{\alpha_{i l}^{j}} D_{i l\left(\zeta_{l}\right)}^{\alpha},
$$

in which $D_{i l\left(\zeta_{l}\right)}^{\alpha}$ is the convex domain of the space of variables $\Delta p_{i l\left(\zeta_{l}\right)}$ and $\Delta y_{i-k, q}^{p}$ formed by the intersection $2^{\alpha_{i l}^{j}+q_{i l(\zeta l)}}$ of subspaces:

$$
\begin{gathered}
\sum_{q \in J_{i l\left(\zeta_{l}\right)}} \frac{\Delta p_{q}}{\delta_{i l\left(\zeta_{l}\right)}^{\alpha q}}+\sum_{q \in I_{i-k}^{l}} \sum_{\lambda=1}^{\alpha_{i-k, q}^{l}} \frac{\Delta y_{i-k, q}^{l \lambda}}{\delta_{i l\left(\zeta_{l}\right)}^{\alpha \lambda} \leq 1} \\
\sum_{q \in J_{i l\left(\zeta_{l}\right)}} \frac{\Delta p_{q}}{\gamma_{i l\left(\zeta_{l}\right)}^{\alpha q}}+\sum_{q \in I_{i-k}^{l}} \sum_{\lambda=1}^{\alpha_{i-k, q}^{l}} \frac{\Delta y_{i-k, q}^{l \lambda}}{\gamma_{i l\left(\zeta_{l}\right)}^{\alpha \lambda}} \leq 1
\end{gathered}
$$

Here

$$
\delta_{i l\left(\zeta_{l}\right)}^{\alpha r}=\left\{\begin{array}{c}
\tilde{\delta}_{i l\left(\zeta_{l}\right)}^{\alpha r}, \quad \text { if } y_{r(+)}^{\alpha} \leq y_{i l(0)}^{j \alpha}+\varepsilon_{i l}^{j \alpha}, \\
\tilde{\gamma}_{i l\left(\zeta_{l}\right)}^{\alpha r}=\frac{\varepsilon_{i l}^{j \alpha} \widetilde{\delta}_{i l\left(\zeta_{l}\right)}^{\alpha r}}{y_{i l(0)}^{j \alpha}-y_{r(+)}^{\alpha}}, \\
\text { if } y_{r(+)}^{\alpha}>y_{i l(0)}^{j \alpha}+\varepsilon_{i l}^{j \alpha},
\end{array}\right.
$$

And value $\gamma_{i l\left(\zeta_{l}\right)}^{\alpha r}$ is determined as:

$$
\begin{gathered}
\gamma_{i l\left(\zeta_{l}\right)}^{\alpha r}=\left\{\begin{array}{c}
-\delta_{i l\left(\zeta_{l}\right)}^{\alpha r}, \text { if } y_{r(-)}^{\alpha} \leq y_{i l(0)}^{j \alpha}+\varepsilon_{i l}^{j \alpha}, \\
\frac{\varepsilon_{i l}^{j \alpha} \widetilde{\delta}_{i l\left(\zeta_{l}\right)}^{\alpha r}}{y_{r(-)}^{\alpha}-y_{i l(0)}^{j \alpha}}, \text { if } y_{r(-)}^{\alpha}>y_{i l(0)}^{j \alpha}+\varepsilon_{i l}^{j \alpha},
\end{array}\right. \\
\tilde{\delta}_{i l\left(\zeta_{l}\right)}^{\alpha r}=-\frac{\varepsilon_{i l}^{j \alpha}}{h_{i l}^{\alpha r}}, \\
y_{r(+)}^{\alpha}=y_{i l}^{j \alpha}\left(p_{1(0)}, \ldots, p_{r-1(0)}, p_{r}+\widetilde{\delta}_{i l\left(\zeta_{l}\right)}^{\alpha r}, p_{r+1(0)},\right. \\
\ldots, y_{i l(0)}^{j} \forall r \in 1, \ldots, q_{i l\left(\zeta_{l}\right)}+\alpha_{i l}^{j}, \\
y_{r(-)}^{\alpha}=y_{i l}^{j \alpha}\left(p_{1(0)}^{l}, y_{i l(0)}^{j 1}, \ldots, y_{i l(0)}^{j, r-1}, y_{i l(0)}^{j r}-\widetilde{\delta}_{i l\left(\zeta_{l}\right)}^{\alpha r},\right. \\
\left.y_{i l(0)}^{j, r+1}, \ldots\right) \quad \forall r \in 1, \ldots, q_{i l\left(\zeta_{l}\right)}+\alpha_{i l}^{j},
\end{gathered}
$$

$$
h_{i l}^{\alpha r}=\left.\frac{\partial y_{i l}^{j \alpha}}{\partial p^{r}}\right|_{0} \forall r \in 1, \ldots, q_{i l\left(\zeta_{l}\right)}+\alpha_{i l}^{j} .
$$

Systems of inequalities (4) are constructed by successively replacing the first inequality of $\delta$ value on the value of $\gamma$ firstly in one member, then in two members, etc. By the value $y_{r(+)}^{\alpha}$ we indicated values of the output variable when the values of the parameters or initial conditions are increased by the value $\widetilde{\delta}_{i l\left(\zeta_{l}\right)}^{\alpha r}$, and $y_{r(-)}^{\alpha}$ are reduced by the same value. By $h_{i l}^{\alpha r}$ we indicated functions of sensitivity of output variables for parameters and initial conditions in nominal points.

The area of permissible variations of initial conditions and parameters we consider in positive orthant (due to the symmetrical shape of restrictions on assignment variations of initial conditions and parameters). It is defined by the inequalities (4) and can be written as:

$$
D_{i l\left(\zeta_{l}\right)}=\bigcap_{\alpha=1}^{\alpha_{i l}^{j}} D_{i l\left(\zeta_{l}\right)}^{\alpha},
$$

where

$$
\begin{gathered}
D_{i l\left(\zeta_{l}\right)}^{\alpha}: \sum_{q \in J_{i l\left(\zeta_{l}\right)}} \frac{\Delta p_{i l\left(\zeta_{l}\right)}^{q}}{a_{i l\left(\zeta_{l}\right)}^{\alpha q}}+\sum_{\lambda=1}^{\alpha_{i l}^{j}} \frac{\Delta y_{i l}^{j \lambda}}{a_{i l\left(\zeta_{l}\right)}^{\alpha \lambda}} \leq 1, \\
a_{i l\left(\zeta_{l}\right)}^{\alpha r}=\min \left\{\left|\delta_{i l\left(\zeta_{l}\right)}^{\alpha r}\right|,\left|\gamma_{i l\left(\zeta_{l}\right)}^{\alpha r}\right|\right\} ;\left(r=1, \ldots, q_{i l\left(\zeta_{l}\right)}+\alpha_{i l}^{j}\right),
\end{gathered}
$$
and values $\delta_{i l\left(\zeta_{l}\right)}^{\alpha r}$ and $\gamma_{i l\left(\zeta_{l}\right)}^{\alpha r}$ are determined by relations (5), (6).

On the basis of presented relationships we form the dropout condition of SOM options for the acting SSR.

If the control law $u_{i-k, q\left(\zeta_{l}\right)}$ of the $q$-th subsystem of the $i$ - $k$-th level at nominal values of the parameters leads to the variations of the output variables $\Delta y_{i-k\left(\zeta_{l}\right)}^{l}$ which do not belong to the domain:

$$
D_{i l}^{(0)}=\bigcup_{\zeta_{l}=1}^{\xi_{i l}} D_{i l\left(\zeta_{l}\right)},
$$

at minimal variations of parameters of control lows $u_{i l\left(\zeta_{l}\right)} \in U_{i l}$, i.e.:

$$
\Delta y_{i-k\left(\zeta_{l}\right)}^{l} \notin D_{i l}^{(0)}=\left.\bigcup_{\zeta_{l}=1}^{\xi_{i l}} D_{i l\left(\zeta_{l}\right)}\right|_{\Delta p_{i l\left(\zeta_{l}\right) \min }},
$$

it will not form a system of options with control laws from the set $U_{i l}$ satisfying the inequality (3).

Conclusions. Thus, at conditions of network-centric organizations of management of operational services of the power system screening options of subsystems of the $i$ - $k$-th level when checking the condition (11) allows you to obtain the maximum number of principally possible SOM creation variants taking into account adopted SSR by narrowing the set of technical implementation of the $l$-th subsystem of the $i$-th level. 


\section{REFERENCES}

1. Kobets B.B., Volkov I.O. Smart Grid - Conceptual provisions. Energorynok - Energy Market, 2010. no.3(75), pp. 67-72. (Rus).

2. Shidlovskii A.K., Vypanasenko S.I., Vorohov L.P. Tendentsiyi rozvytku enerhetyky Ukrayiny [Trends in Energy Ukraine]. Donetsk, National Mining University Publ., 2005. 104 p. (Ukr).

3. Kirilenko O.V., Denysyuk S.P., Rybina O.B., Batalov A.G. Features Integration of IPS Ukraine into the European system UCTE. Tekhnichna elektrodynamika. Tem. vypusk «Silova elektronika $i$ energoefektivnist» - Technical electrodynamics. Thematic issue "Power electronics \& energy efficiency», 2006, vol.1, pp. 63-68. (Ukr)

4. Bojtsov Y.A., Vasiljev A.P. The solution of a problem of rational architecture of system of operative service of electrical networks. Izvestiia vysshikh uchebnykh zavedenii. Problemy energetiki - Proceedings of the higher educational institutions. Energy sector problems, 2008, no.1-2, pp. 56-63. (Rus).

5. Burmistrov V.N., Drogunov S.V. Perspective innovative directions of development of power. Elektrika-Electrics, 2011, no.5, pp. 9-12. (Rus).

6. Massel L.V., Ivanov R.A. Possibility of application of situational awareness in energy research. Proceedings of the Workshop on Computer Science and Informational Technologies (CSIT-2010), Russia, Moscow - St.Petersburg, 1319 September, 2010. Vol.1, Ufa State Aviation Technical University, 2010. pp. 185-187.

How to cite this article:

Sokol Ye.I., Gryb O.G., Shvets S.V. Network centrism optimization of expeditious service of elements of the power supply system. Electrical engineering \& electromechanics, 2016, no.3, pp. 67-72. doi: 10.20998/2074-272X.2016.3.11.
7. News and priorities of energy: Digest. Novyny enerhetyky News energy, 2005, no.9, p. 50. (Ukr).

8. Titov N.N. Povyshenie nadezhnosti $i$ kachestva funktsionirovaniia avtomatizirovannykh sistem dispetcherskogo upravleniia elektroenergeticheskimi sistemami [Increase of reliability and quality of functioning of the automated systems of dispatching management of electrical power systems]. Kharkiv, Fact Publ., 2013. 200 p. (Rus).

Received 29.03.2016

Ye.I. Sokol ${ }^{1}$, Doctor of Technical Science, Professor,

Corresponding Member of the National Academy of Science of Ukraine,

O.G. Gryb ${ }^{1}$, Doctor of Technical Science, Professor,

S.V. Shvets ${ }^{2}$, Candidate of Technical Science, Associate Professor

${ }^{1}$ National Technical University «Kharkiv Polytechnic Institute», 21, Frunze Str., Kharkiv, 61002, Ukraine.

${ }^{2}$ O.M. Beketov National University of Urban Economy in Kharkiv,

17, Marshal Bazhanov Str., Kharkiv, 61002, Ukraine, phone +380 67 7680838, e-mail: se_sx@bk.ru 